\title{
PENGUKURAN KUALITAS LAYANAN TERHADAP KEPUASAN PELANGGAN (STUDI PADA RUMAH MAKAN CEPAT SAJI OLIVE FRIED CHICKEN DI JALAN GLAGAHSARI YOGYAKARTA)
}

\author{
Amadea Deviona \\ amadea.deviona@yahoo.com \\ Universitas Ahmad Dahlan \\ Fitroh Adhilla \\ fitauad@yahoo.com \\ Universitas Ahmad Dahlan
}

\begin{abstract}
ABSTRAK
This study aims to find out how the influence of quality service to customer satisfaction Olive fried chicken at Glagahsari Yogyakarta. And to find out what variables are influential significant to customer satisfaction both partially and simultaneously. Primary data obtained from the results of the distribution of questionnaires to consumers who consume at Olive fried chicken at Glagahsari Yogyakarta, sample and sampling techniques using the side accidental method and purposive sampling. And selected consumers aged over 17 years. Processing the data of this research is using multivariate statistical methods. with technique multiple linear regression analysis, partial test ( $t$ test), and simultaneous test ( $F$ test). Partial Test Results (t test) variables of food quality (X2), communication (X4), and benefit relationship (X5) does not affect customer satisfaction (Y). While for physical environment variables (X1), customer orientation (X3), and price (X6) it was concluded that the partial test (t test) had an effect on satisfaction customer (Y) in consuming Olive freid chicken at Glagahsari Yogyakarta. From the calculation results of the simultaneous test (F test), obtained Sig $<\alpha=5 \%$ or $0,000<5 \%$, because Sig $<\alpha=5 \%$. Then it can be concluded that the variable physical environment (X1), food quality (X2), customer orientation (X3), communication (X4), the benefits of the relationship (X5), and price (X6) that simultaneously test (F test) effect on customer satisfaction (Y) Olive fried fast food restaurant chicken at Glagahsari Yogyakarta.
\end{abstract}

Keywords: Quality Service, Customer Satisfaction, Olive Fried Chicken.

\begin{tabular}{l}
\hline \multicolumn{4}{c}{ PENDAHULUAN } \\
Beberapa tahun belakangan ini \\
khususnya di Indonesia, bidang usaha \\
kuliner sangat berkembang pesat. Usaha \\
ekonomi yang satu ini menjanjikan \\
prospek yang sangat bagus dan \\
mempunyai perkembangan yang sangat \\
luas serta menguntungkan. \\
Berkembangnya usaha kuliner, mulai dari \\
yang ditawarkan pedagang kaki lima \\
dipinggir jalan, sampai dengan restoran \\
mewah yang menyajikan berbagai menu \\
baik menu tradisional sampai dengan
\end{tabular}

menu internasional merupakan bukti bahwa bidang usaha ini sangat menjanjikan.

Perkembangan kuliner di Indonesia sendiri pada tahun 2011 di sektor makanan dan minuman menyumbang Rp 650 triliun, pendapatan Negara dan 30\% dari BTP (Bahan Tambahan Pangan). Di kota Yogyakarta, bidang usaha kuliner juga mengalami perkembangan yang sangat pesat, kususnya kuliner yang berbahan dasar daging ayam. Di Yogyakarta kejayaan kuliner berbahan dasar daging ayam memang mempunyai sejarah 
panjang. Diawali dengan Ayam goreng Mbok Berek yang sangat terkenal, disusul kemudian Ayam goreng Ny Suharti dan seterusnya. Hingga saat ini jumlah kuliner berbahan dasar ayam sudah sangat banyak yang mengakibatkan semakin ketatnya persaingan. Salah satu upaya untuk menghadapi kompetitor/ pesaing dalam industri ini adalah dengan meningkatkan kualitas layanan kepada konsumen. Kualitas layanan yang bermuara pada kepuasan konsumen sangat berperan dalam upaya mencari dan mempertahankan konsumen.

Kepuasan pelanggan merupakan hal yang penting untuk digunakan menarik pelanggan, dimana untuk menciptakan kepuasan pelanggan diperlukan kualitas layanan yang baik. Dengan mengetahui alasan yang mendasar mengapa konsumen melakukan pembelian, maka dapat diketahui strategi yang tepat untuk digunakan membuat kebijakan dalam upaya pemasaran. Dengan kata lain, pihak pemasar harus mengaktualisasikan setiap harapan konsumen menjadi suatu kepuasan atas layanan yang diberikan. Dimana hal tersebut merupakan kunci keberhasilan yang menjadikannya berbeda dari pesaingnya, karena jika tidak demikian maka perusahaan akan ditinggalkan oleh pelanggannya. Semakin disadari bahwa pelanggan merupakan raja bagi perusahaan. Dengan persaingan yang semakin ketat, tanpa memiliki pelanggan tetap perusahaan dengan mudah mengalami resiko kemunduran dalam bisnisnya. Selain kualitas layanan yang baik, hal yang penting untuk diperhatikan adalah penentuan harga, dimana pelanggan merasa puas atas sejumlah uang yang dibelanjakannya.

Harga merupakan variabel penting dalam pemasaran. Menurut Swastha (1981) harga adalah jumlah uang (ditambah beberapa barang kalau mungkin) yang dibutuhkan untuk mendapatkan sejumlah kombinasi dari barang beserta pelayanannya.
Keberhasilan perusahaan dalam memberikan layanan yang berkualitas kepada para pelanggannya, pencapaian pangsa pasar yang tinggi, serta peningkatan laba perusahaan tersebut sangat ditentukan oleh pendekatan yang digunakan Zeithmal (1996) dalam buku Lupiyoadi (2006). Konsekuensi atas pendekatan kualitas jasa suatu produk memiliki esensi penting bagi strategi perusahaan untuk mempertahankan diri dan mencapai kesuksesan dalam menghadapi persaingan. Salah satu pendekatan kulitas jasa yang banyak dijadikan acuan dalam riset pemasaran adalah model SERVQUAL (Service Quality) yang dikembangkan oleh Parasuraman, Zeithmal dan Berry. SERVQUAL dibangun atas dasar adanya perbandingan dua faktor utama, yaitu persepsi pelanggan atas layanan yang nyata mereka terima (perceived service) dengan layanan yang sesungguhnya diharapakan (expected service).

Disini peneliti menggunakan metode Kin et al., (2006) dalam jurnal Vanniarajan (2009) meneliti prediktor dan hasil kualitas hubungan dengan mengacu pada industri restoran mewah yaitu dengan meneliti 6 variabel adalah lingkungan fisik, kualitas makanan orientasi pelanggan, komunikasi, manfaat hubungan, dan harga.

Pada uraian di atas sudah cukup jelas bahwa salah satunya yang ada di Yogyakarta dalam bidang kuliner yang sedang berkembang pesat adalah rumah makan cepat saji Olive fried chicken dan upaya yang harus dilakukan oleh pemilik rumah makan cepat saji ini adalah mengutamakan kualitas layanan dan kualitas produk.

Tujuan dari penelitian ini diantaranya: 1) untuk menguji pengaruh secara parsial variabel lingkungan fisik, kualitas makanan, orientasi pelanggan, komunikasi, manfaat hubungan, dan harga terhadap kepuasan pelanggan rumah makan cepat saji Olive fried chicken di Jalan Glagahsari Yogyakarta dan 2) untuk 
menguji pengaruh secara simultan variabel lingkungan fisik, kualitas makanan, orientasi pelanggan, komunikasi, manfaat hubungan, dan harga terhadap kepuasan pelanggan rumah makan cepat saji Olive fried chicken di Jalan Glagahsari Yogyakarta.

\section{REVIEW LITERATUR DAN HIPOTESIS}

\section{Landasan Teori}

1. Manajemen Pemasaran

Manajemen pemasaran yang dirumuskan American Marketing Association (dalam Kotler, 1999) adalah proses perencanaan dan pelaksanaan konsepsi, penentuan harga, dan distribusi barang, jasa dan gagasan untuk menciptakan pertukaran dengan kelompok sasaran yang memenuhi tujuan pelanggan dan organisasi.

\section{Kepuasan Pelanggan}

Kepuasan adalah perasaan senang atau kecewa seseorang yang muncul setelah membandingkan kinerja atau hasil produk yang dipikirkan terhadap kinerja yang diharapkan. Jika kinerja memenuhi harapan, pelanggan puas dan jika kinerja melebihi harapan maka pelanggan amat puas atau senang (Kotler, 2009).

\section{Lingkungan Fisik}

Lingkungan fisik adalah salah satu unsur yang harus didaya gunakan oleh organisasi sehingga menimbulkan rasa nyaman, tentram, dan dapat meningkatkan hasil kerja yang baik untuk meningkatkan kinerja organisasi tersebut (Sihombing, 2004).

\section{Kualitas Makanan}

Menurut Amanah (2010) kulitas makanan adalah kualitas produk makanan memiliki pengaruh terhadap kepuasan pelanggan, sehingga akan lebih baik bila dapat meningkatkan dan mempertahankan kualitas produk makanan sebagai strategi pemasaran.

5. Orientasi Pelanggan

Orientasi pelanggan adalah perusahaan harus berorientasi pada pelanggan bukan berorientasi pada perusahaan, hal ini untuk memberkan pelayanan yang terbaik pada konsumen dapat menimbulkan rasa loyalitas konsumen terhadap pelanggan (Kotler, 1997).

\section{Komunikasi}

Burgo (2002) Komunikasi adalah sebuah proses pemikiran berupa seleksi informasi (kognitif), menilai atau mempersepsikan pengalaman (afektif) dan bertindak balas terhadap informasi yang disampaikan tersebut (psikomotorik).

7. Manfaat Hubungan

Manfaat hubungan adalah dimana seorang individu atau dengan kelompok melakukan interaksi dan kerjasama. Untuk pencapaian hasil interaksi dan kerjasama tersebut (Burgo, 2002).

\section{Harga}

Harga adalah jumlah uang yang ditagihkan untuk suatu produk atau jasa, jumlah nilai yang dipertukarkan konsumen untuk manfaat memiliki atau menggunakan produk atau jasa (Kotler, 2005).

\section{Penelitian Terdahulu}

Vanniarajan (2009). Dari 32 variabel DINESERV, ada 6 variabel yang berpengaruh kuat pada kualitas layanan dapat diidentifikasi sebagai kualitas yang konsisten dari makanan dan minuman adalah nilai beta menjadi 0,2817 , yang mengungkapkan pengaruh kuat pada keseluruhan layanan kualitas. Dalam kasus hubungan fungsi manfaat, variabel yang paling pengaruh yang signifikan pada layanan secara keseluruhan kualitas hubungan pribadi adalah beta co-efficien 
menjadi 0,2504. Demikian pula, dalam kasus empati dan keadilan harga fungsi, pengaruh terkuat adalah melihat dalam kasus ramah dengan restuarant staf dan makanan yang masuk akal harga mereka adalah beta co-efficien menjadi 0,2099 dan masing-masing 0,1738. Sehubungan dengan variabel berwujud dan fungsi komunikasi, variabel ini bersih dan elegan peralatan makan, dan konsisten komunikasi beta mereka adalah co-efficien menjadi 0,1503 dan 0,1286 masingmasing.

\section{Hipotesis}

H1: Diduga ada pengaruh secara parsial variabel lingkungan fisik, kualitas makanan, orientasi pelanggan, komunikasi, manfaat hubungan, dan harga terhadap kepuasan pelanggan rumah makan cepat saji Olive fried chicken di Jalan Glagahsari Yogyakarta.

H2: Diduga ada pengaruh secara simultan variabel lingkungan fisik, kualitas makanan, orientasi pelanggan, komunikasi, manfaat hubungan, dan harga terhadap kepuasan pelanggan rumah makan cepat saji Olive fried chicken di Jalan Glagahsari Yogyakarta.

\section{METODE PENELITIAN}

\section{Populasi dan Sampel}

Definisi populasi adalah sekelompok orang, kejadian atau segala sesuatu yang mempunyai karakteristik tertentu (Indrianto, 2002). Populasi ialah gabungan dari seluruh elemen yang berbentuk peristiwa hal, atau orang yang memiliki karakteristik serupa yang menjadi pusat semesta penelitian (Ferdinand, 2006). Dengan demikian populasi dalam penelitian ini adalah seluruh konsumen Rumah Makan Cepat Saji Olive Fried Chicken di Jalan Glagahsari Yogyakarta.
Definisi sampel adalah peneliti dapat meneliti seluruh elemen populasi (disebut dengan sensus) atau meneliti sebagian dari elemenelemen populasi (disebut dengan penelitian sampel) (Indrianto, 2002). Sampel menurut Sugiyono (2004) adalah bagian dari jumlah dan karakteristik yang dimiliki oleh populasi tersebut. Sampel merupakan bagian yang berguna bagi tujuan penelitian populasi dan aspekaspeknya.

Metode pengambilan sampel dalam penelitian ini dilakukan dengan cara accidental sampling dan menggunakan purposive sampling yang merupakan bagian dari non probability sampling. Bentuk pengambilan sampel ini berdasarkan kebetulan, yaitu siapa saja yang bertemu dengan peneliti dan dianggap cocok menjadi sumber data akan menjadi sampel penelitian ini (Sugiyono, 2004) yaitu semua masyarakat yang membeli atau mengkonsumsi ditempat Olive fried chicken di Jalan Glagahsari Yogyakarta.

Untuk mendapatkan informasi dari setiap anggota populasi, peneliti menentukan sampel atau sejenis yang bisa mewakili populasi dalam jumlah tertentu. Sampel yang digunakan dalam penelitian ini adalah konsumen rumah makan cepat saji Olive fried chicken di Jalan Glagahsari Yogyakarta yang makan ditempat. Kemudian dipilih secara spesifik yang sudah berusia 17 tahun keatas dan kunjungan ke rumah makan cepat saji Olive di Jalan Glagah Sari Yogyakarta.

\section{Definisi Operasional}

1. Variabel Independen

a. Lingkungan Fisik

Lingkungan fisik adalah salah satu unsur yang harus didaya gunakan oleh organisasi sehingga menimbulkan rasa nyaman, tentram, dan dapat meningkatkan hasil kerja yang baik untuk meningkatkan kinerja organisasi tersebut (Sihombing, 2004). 
b. Kondisi Makanan

Menurut Amanah (2010) kulitas makanan adalah kualitas produk makanan memiliki pengaruh terhadap kepuasan pelanggan, sehingga akan lebih baik bila dapat meningkatkan dan mempertahankan kualitas produk makanan sebagai strategi pemasaran.

c. Orientasi Pelanggan

Orientasi pelanggan adalah perusahaan harus berorientasi pada pelanggan bukan berorientasi pada perusahaan, hal ini untuk memberkan pelayanan yang terbaik pada konsumen dapat menimbulkan rasa loyalitas konsumen terhadap pelanggan (Kotler, 1997).

d. Komunikasi

Burgo (2002) Komunikasi adalah sebuah proses pemikiran berupa seleksi informasi (kognitif), menilai atau mempersepsikan pengalaman (afektif) dan bertindak balas terhadap informasi yang disampaikan tersebut (psikomotorik).

e. Manfaat Hubungan

Manfaat hubungan adalah dimana seorang individu atau dengan kelompok melakukan interaksi dan kerjasama. Untuk pencapaian hasil interaksi dan kerjasama tersebut (Burgo, 2002).

f. Harga

Harga adalah jumlah uang yang ditagihkan untuk suatu produk atau jasa, jumlah nilai yang dipertukarkan konsumen untuk manfaat memiliki atau menggunakan produk atau jasa (Kotler, 2005).

\section{Variabel Dependen}

Variabel dependen (Y) yang digunakan dalam penelitian ini adalah kepuasan pelanggan. Kepuasan adalah perasaan senang atau kecewa seseorang yang muncul setelah membandingkan kinerja atau hasil produk yang dipikirkan terhadap kinerja yang diharapkan. Jika kinerja memenuhi harapan, pelanggan puas dan jika kinerja melebihi harapan maka pelanggan amat puas atau senang (Kotler, 2009).

\section{Uji Instrumen}

1. Uji Validitas

Validitas suatu alat ukur adalah apakah suatu alat ukur dapat mengukur apa yang sebenarnya ingin diukur. Uji validitas perlu dilakukan untuk mengetahui sejauh mana suatu alat ukur yang digunakan dalam penelitian dapat mengukur apa yang sebenarnya ingin peneliti ukur atau dapat digunakan untuk menguji instrumen penelitian agar instrumen tersebut dapat memberikan hasil sesuai dengan tujuannya (Cooper, 2001).

Pengujian validitas yang dilakukan adalah construct validity dengan metode confirmatory factor analysis yang dilakukan dengan bantuan program SPSS. Analisis faktor digunakan dalam analisis penelitian ini karena merupakan salah satu metode statistik multivariate yang tujuan utamanya untuk meringkas atau mengurangi data atau variabel yang akan diperlukan untuk dianalisis. Analisis faktor memecahkan masalah yang menyangkut hubungan timbal balik antara sejumlah indikator dan kemudian menjelaskan keterkaitan antar indikator ke dalam dimensi-dimensi yang mendasari hubungan tersebut. Dan karena item-item pertanyaan dalam kuesioner diadopsi dari penelitian sebelumnya dengan dimodifikasi maka analisis faktor yang dilakukan bersifat confirmatory, yaitu saat pengolahan pada tahap extraction dipilih number of factor adalah 7 sesuai dengan variabel yang diuji dalam model penelitian. Kriteria signifikansi terhadap item-item pertanyaan dalam penelitian ini didasarkan pada signifikansi praktis (practical significance) (Hair et al., 
1998), seperti terlihat pada tabel 3 berikut:

Signifikansi Faktor Loading

\begin{tabular}{|l|l|}
\hline \multicolumn{1}{|c|}{ Faktor Loading } & \multicolumn{1}{c|}{ Keterangan } \\
\hline Lebih besar dari 0.30 & Level minimal \\
\hline Lebih besar dari 0.40 & Sangat Penting \\
\hline Lebih besar dari 0.50 & Signifikan \\
\hline
\end{tabular}

Pedoman umum yang dipakai adalah semakin besar factor loading semakin penting indikator tersebut dalam menafsirkan suatu faktor (Hair $e t$ al., 1998). Item-item yang mempunyai factor loading kurang dari 0,40 akan dikeluarkan karena dianggap hanya mempunyai kemampuan menafsirkan suatu faktor pada level minimum. Sedangkan item yang mempunyai factor loading lebih besar dari 0,40 dianggap signifikan dan bisa dimasukkan sebagai anggota suatu faktor.

Dari hasil reliabilitas, dilakukan analisis faktor terhadap item-item yang telah memenuhi nilai reliabilitas dengan memasukkan semua item tersebut dan kemudian mengeliminasi item tersebut satu per satu bagi item yang tidak memenuhi persyaratan seperti dijelaskan sebelumnya, yaitu memiliki lebih dari satu nilai loading yang mirip pada beberapa faktor yang berbeda, memiliki nilai loading yang lebih besar pada faktor lain dibandingkan pada faktornya, atau tidak memiliki nilai loading pada faktornya.

\section{Uji Reliabilitas}

Uji reliabilitas untuk menguji ketepatan instrumen pengukur dengan konsistensi diantara butir-butir pernyataan dalam suatu instrumen. Reliabilitas berkaitan dengan ketepatan prosedur pengukuran dan konsistensi. Suatu alat ukur yang dinilai reliabel jika pengukur tersebut menunjukkan hasilhasil yang konsisten dari waktu ke waktu.
Peneliti menguji instrumen penelitian dengan sampel sejumlah 130 responden. Koefisien reliabilitas ditunjukkan oleh koefisien Cronbach Alpha yang berkisar antara 0 sampai 1 . Semakin tinggi nilai koefisien Cronbach Alpha berarti semakin tinggi reliabilitas alat ukur yang digunakan. Untuk menguji reliabilitas dalam penelitian ini adalah dengan membandingkan Cronbach Coefficient Alpha (r Alpha) pada hasil olahan SPSS Release 16.0 dengan Rule of Thumb/ Kesepakatan Umum dari koefisien alfa yaitu lebih besar dari 0,6 untuk penelitian eksploratori.

\section{Teknik Analisis Data}

1. Analisis Regresi Berganda

Model regresi adalah model yang digunakan untuk menganalisis pengaruh dari berbagai variabel independen terhadap satu variabel dependen (Ferdinand, 2006). Formula untuk regresi linear berganda adalah sebagai berikut:

$$
\mathrm{Y}=\mathrm{a}+\beta 1 \mathrm{X} 1+\beta 2 \mathrm{X} 2+\beta 3 \mathrm{X} 3+\beta 4
$$$$
\mathrm{X} 4+\beta 5 \mathrm{X} 5+\beta 6 \mathrm{X} 6
$$

Dimana:

$\mathrm{Y}=$ Kepuasan pelanggan

$\mathrm{a}=$ Konstanta

$\mathrm{X} 1$ = Lingkungan fisik

$\beta 1=$ Koefisien regresi lingkungan fisik

$\mathrm{X} 2$ = Kualitas makanan

$\beta 2=$ Koefisien regresi kualitas makanan

$\mathrm{X} 3=$ Orientasi pelanggan

$\beta 4=$ Koefisien regresi orientasi

pelanggan

$\mathrm{X} 4=$ Komunikasi

$\beta 4=$ Koefisien regresi komunikasi

X5= Manfaat hubungan

$\beta 5=$ Koefisien regresi manfaat hubungan

X6= Harga

$\beta 6=$ Koefisien regresi harga 


\section{Uji Hipotesis}

\section{Uji Parsial (Uji T)}

Untuk menentukan koefisien spesifik yang mana yang tidak sama dengan nol, uji tambahan diperlukan yaitu dengan menggunakan uji t. Dasar pengambilan keputusan (Ghozali, 2005) adalah dengan menggunakan angka probabilitas signifikan, yaitu:

Apabila angka probabilitas signifikan > 0.05, maka Ho diterima dan Ha ditolak. Apabila angka probabilitas signifikan < 0.05, maka Ho ditolak dan Ha diterima.

\section{Uji Simultan (Uji F)}

Penelitian ini, uji $\mathrm{F}$ digunakan untuk mengetahui tingkat signifikan pengaruh variabel-variabel independen secara bersama-sama (simultan) terhadap variabel dependen (Ghozali, 2005). Dalam penelitian ini, hipotesis yang digunakan adalah:

Apabila probabilitas signifikan $>0.05$, maka Ho diterima dan Ha ditolak.

Apabila probabilitas signifikan $<0.05$, maka Ho ditolak dan Ha diterima.

\section{Uji Koefisien Determinasi}

Koefisien determinasi (R2) pada intinya mengukur seberapa jauh kemampuan sebuah model menerangkan variasi variabel dependen (Ghozali, 2005).

\section{HASIL PENELITIAN DAN PEMBAHASAN}

\section{Hasil Penelitian}

1. Hasil Uji Validitas

Peneliti telah melakukan uji instrumen (uji pertama) dan hasil dari uji instrumen tersebut bahwa X1.4, Y2, dan Y6 indikator tersebut tidak valid. Karena terbentuk sebanyak 2 komponen dan indikator tersebut harus dikeluarkan dari perhitungan agar terbentuk 1 komponen dan dinyatakan valid.

Hasil Uji Validitas

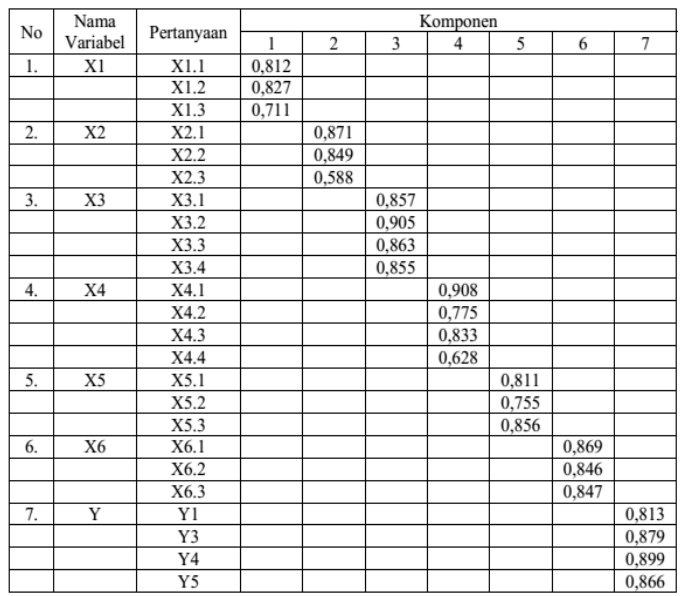

Dari data dijelaskan bahwa tabel di atas, bahwa indikator dikeluarkan X5.4 dan X6.4 dinyatakan tidak valid. Karena factor loading di bawah 0,50, dianggap mempunyai signifikan. Setelah melakukan pengolahan data kembali dinyatakan semua variabel indikator valid. Karena masing-masing variabel terbentuk 1 komponen dan factor loading diatas 0,50 .

\section{Hasil Uji Reliabilitas}

Kriteria uji reliabilitas dapat dinyatakan reliabel, jika nilai Cronbach's Alpha lebih besar dari nilai kritis sebesar 0,60. Berdasarkan penelitian uji instrumen (uji pertama), bahwa indikator X1.4 memiliki nilai Cronbach's Alpha sebesar 0,555 dengan melihat kolom Cronbach's Alpha. Maka indikator dihilangkan 
untuk mendapatkan nilai Cronbach's Alpha diatas 0,6, sehingga indikator dikeluarkan dalam pengukuran.

Penelitian uji instrumen (uji kedua), hasilnya tidak reliabel pada indikator X5.4. Karena indikator tersebut dibawah nilai kritis. Peneliti melakukan penghapusan pada indikator X5.4, pengolahan data kembali dilakukan. Hasil yang didapat semua indikator reliabel. Bahwa dapat dinyatakan dan dengan sesuai kriteria pengujian reliabilitas, maka uji instrumen penelitian kuesioner yang digunakan dalam penelitian ini dinyatakan reliabel.

Hasil Uji Reliabilitas

\begin{tabular}{|c|c|c|c|c|}
\hline No & Nama Variabel & Nilai Cronbach's Alpha & Nilai Kritis & Keterangan \\
\hline 1. & X1 & 0,686 & 0,60 & Reliabel \\
\hline 2. & X2 & 0,653 & 0,60 & Reliabel \\
\hline 3. & X3 & 0,891 & 0,60 & Reliabel \\
\hline 4. & X4 & 0,784 & 0,60 & Reliabel \\
\hline 5. & X5 & 0,737 & 0,60 & Reliabel \\
\hline 6. & X6 & 0,747 & 0,60 & Reliabel \\
\hline 7. & Y & 0,885 & 0,60 & Reliabel \\
\hline
\end{tabular}

3. Hasil Uji Regresi Linier Berganda

Hasil Analisis Regresi Linier Berganda

\begin{tabular}{|l|r|r|r|}
\hline \multirow{2}{*}{ Model } & \multicolumn{2}{|c|}{ Unstandardized Coefficients } & \multirow{2}{*}{$\mathrm{N}$} \\
\cline { 2 - 3 } & \multicolumn{1}{|c|}{$\mathrm{B}$} & \multicolumn{1}{c|}{ Std. Error } & \multicolumn{1}{c|}{} \\
\hline (Constant) & $-2.219 \mathrm{E}-16$ & .060 & 100 \\
\hline $\begin{array}{l}\text { Lingkungan fisik } \\
\left(\mathrm{X}_{1)}\right.\end{array}$ & .234 & .078 & 100 \\
\hline $\begin{array}{l}\text { Kualitas makanan } \\
\left(\mathrm{X}_{2}\right)\end{array}$ & .080 & .088 & 100 \\
\hline $\begin{array}{l}\text { Orientasi pelanggan } \\
\left(\mathrm{X}_{3}\right)\end{array}$ & .231 & .079 & 100 \\
\hline Komunikasi $\left(\mathrm{X}_{4}\right)$ & .101 & .069 & 100 \\
\hline $\begin{array}{l}\text { Manfaat hubungan } \\
\left(\mathrm{X}_{5}\right)\end{array}$ & .192 & .094 & 100 \\
\hline Harga $\left(\mathrm{X}_{6}\right)$ & .260 & .081 & 100 \\
\hline
\end{tabular}

Berdasarkan hasil perhitungan tabel di atas, diperoleh persamaan regresi linier berganda sebagai berikut: $\mathrm{Y}=-2,219 \mathrm{E}-16+0,234 \mathrm{X} 1+0,080$ $\mathrm{X} 2+0,231 \mathrm{X} 3+0,101 \mathrm{X} 4+0,192 \mathrm{X} 5$ $+0,260 \times 6$

Nilai konstanta adalah -2,219E16, yang artinya variabel lingkungan fisik (X1), kualitas makanan (X2), orientasi pelanggan (X3), komunikasi (X4), manfaat hubungan (X5), harga (X6). Maka kepuasan pelanggan (Y) dengan nilai sebesar -2,219E-16.
Koefisien regresi untuk variabel nilai b1 adalah 0,234 , yang artinya jika terjadi kenaikan lingkungan fisik (X1) sebesar satu satuan. Maka kepuasan pelanggan (Y) akan naik sebesar 0,234, dalam mengkonsumsi di rumah makan cepat saji Olive fried chicken di Jalan Glagahsari Yogyakarta.

Koefisien regresi untuk variabel nilai b2 adalah 0,080, yang artinya jika terjadi kenaikan kualitas makanan (X2) sebesar satu satuan, maka kepuasan pelanggan (Y) akan naik sebesar 0,080, dalam mengkonsumsi di rumah makan cepat saji Olive fried chicken di Jalan Glagahsari Yogyakarta.

Koefisien regresi untuk variabel nilai b3 adalah 0,231 , yang artinya jika terjadi kenaikan orientasi pelanggan (X3) sebesar satu satuan, maka kepuasan pelanggan (Y) akan naik sebesar 0,231, dalam mengkonsumsi di rumah makan cepat saji Olive fried chicken di Jalan Glagahsari Yogyakarta.

Koefisien regresi untuk variabel nilai b4 adalah 0,101 , yang artinya jika terjadi kenaikan komunikasi (X4) sebesar satu satuan, maka kepuasan pelanggan (Y) akan naik sebesar 0,101, dalam mengkonsumsi di rumah makan cepat saji Olive fried chicken di Jalan Glagahsari Yogyakarta.

Koefisien regresi untuk variabel nilai b5 adalah 0,192 , yang artinya jika terjadi kenaikan manfaat hubungan (X5) sebesar satu satuan, maka kepuasan pelanggan (Y) akan naik sebesar 0,192, dalam mengkonsumsi di rumah makan cepat saji Olive fried chicken di Jalan Glagahsari Yogyakarta.

Koefisien regresi untuk variabel nilai b6 adalah 0,260 , yang artinya jika terjadi perubahan harga (X6) yang lebih murah sebesar satu satuan, maka kepuasan pelanggan (Y) akan naik sebesar 0,260, dalam mengkonsumsi di rumah makan cepat saji Olive fried chicken jalan Glagahsari Yogyakarta. 
4. Hasil Uji Parsial (Uji T)

Hasil analisis Uji Parsial (Uji t)

\begin{tabular}{|l|r|r|r|r|r|}
\hline \multirow{2}{*}{ Model } & \multicolumn{2}{|c|}{$\begin{array}{c}\text { Unstandardized } \\
\text { Coefficients }\end{array}$} & $\begin{array}{r}\text { Standardized } \\
\text { Coefficients }\end{array}$ & \multirow{2}{*}{$\mathrm{t}$} & \multirow{2}{*}{ Sig } \\
\cline { 2 - 4 } & \multicolumn{1}{|c|}{ B } & Std. Error & \multicolumn{1}{c|}{ Beta } & & \\
\hline (Constant) & $-2.219 \mathrm{E}-16$ & .060 & & .000 & 1.000 \\
\hline $\begin{array}{l}\text { Lingkungan } \\
\text { Fisik }\left(\mathrm{X}_{1}\right)\end{array}$ & .234 & .078 & .234 & 3.016 & .003 \\
\hline $\begin{array}{l}\text { Kualitas } \\
\text { Makanan } \\
\left(\mathrm{X}_{2}\right)\end{array}$ & .080 & .088 & .080 & .907 & .366 \\
\hline $\begin{array}{l}\text { Orientasi } \\
\text { Pelanggan } \\
\left(\mathrm{X}_{3}\right)\end{array}$ & .231 & .079 & .231 & 2.909 & .005 \\
\hline $\begin{array}{l}\text { Komunikasi } \\
\left(\mathrm{X}_{4}\right)\end{array}$ & .101 & .069 & .101 & 1.453 & .150 \\
\hline $\begin{array}{l}\text { Manfaat } \\
\text { Hubungan } \\
\left(\mathrm{X}_{5}\right)\end{array}$ & .192 & .094 & .192 & 2.052 & .043 \\
\hline Harga $\left(\mathrm{X}_{6}\right)$ & .260 & .081 & .260 & 3.209 & .002 \\
\hline
\end{tabular}

Uji parsial (Uji t) untuk menguji apakah terdapat pengaruh secara parsial variabel independen yaitu variabel lingkungan fisik (X1), variabel kualitas makanan (X2), orientasi pelanggan (X3), komunikasi (X4), manfaat hubungan (X5), dan harga (X6) apakah mempunyai pengaruh yang signifikan terhadap variabel dependen kepuasan pelanggan $(\mathrm{Y})$.

Hasil df atau degree of freedom

\begin{tabular}{|l|r|r|r|}
\hline \multicolumn{1}{|c|}{ Model } & \multicolumn{1}{c|}{ Df } & \multicolumn{1}{c|}{ F } & \multicolumn{1}{c|}{ Sig } \\
\hline Regression & 6 & 29.833 & $.000^{\mathrm{a}}$ \\
\hline Residual & 93 & & \\
\hline Total & 99 & & \\
\hline
\end{tabular}

a. Pengaruh Lingkungan Fisik

Terhadap Kepuasan Pelanggan.

Hasil perhitungan dengan menggunakan program SPSS 16.0 diperoleh nilai t-hitung sebesar 3,016 . Tingkat signifikansi $\alpha / 2$ adalah 5\%/2 menjadi $2,5 \%$ atau 0,025. Dan df atau degree of freedom adalah 93 dapat dilihat ditabel bagian baris residual. Sedangkan ttabeladalah 1,960.

Nilai t-hitung lebih besar dari t-tabel (t-hitung $=3,016>\mathrm{t}$-tabel $=$ 1,960), dan untuk nilai signifikan $($ Sig $=0,003<0,05)$, maka langkah keputusan dapat dinyatakan $\mathrm{H} 0$ ditolak dan $\mathrm{Ha}$ diterima. Dapat disimpulkan bahwa variabel lingkungan fisik (X1) berpengaruh signifikan, terhadap kepuasan pelanggan (Y) Olive fried chicken di Jalan Glagahsari Yogyakarta.

b. Pengaruh Kualitas Makanan Terhadap Kepuasan Pelanggan.

Hasil perhitungan dengan menggunakan program SPSS 16.0 diperoleh nilai t-hitung sebesar 0,907 . Tingkat signifikansi $\alpha / 2$ adalah 5\%/2 menjadi $2,5 \%$ atau 0,025. Dan df atau degree of freedom adalah 93 dapat dilihat ditabel bagian baris residual. Sedangkan ttabeladalah 1,960.

Nilai t-hitung lebih besar dari t-tabel (t-hitung $=0,907<\mathrm{t}$ tabel=1,960) dan untuk nilai signifikan ( $\mathrm{Sig}=0,366>0,05)$, maka langkah keputusan dapat dinyatakan $\mathrm{HO}$ diterima dan $\mathrm{Ha}$ ditolak. Dan dapat disimpulkan bahwa variabel kualitas makanan (X2) tidak berpengaruh signifikan, terhadap kepuasan pelanggan (Y) Olive fried chicken di Jalan Glagasari Yogyakarta.

Variabel kualitas makanan tidak signifikan, karena konsumen yang mengkonsumsi sejenis fried chicken mempunyai anggapan bahwa kualitas makanan/rasa dari masakan jenis ini relatif sama antara merek satu dengan lainnya atau dianggap relatif standar dalam rasa.

c. Pengaruh Orientasi Pelanggan Terhadap Kepuasan Pelanggan.

Hasil perhitungan dengan menggunakan program SPSS 16.0 diperoleh nilai t-hitung sebesar 2,909. Tingkat signifikansi $\alpha / 2$ adalah 5\%/2 menjadi $2,5 \%$ atau 0,025. Dan df atau degree of freedom adalah 93 dapat dilihat ditabel bagian baris residual. Sedangkan ttabel adalah 1,960.

Nilai t-hitung lebih besar dari t-tabel (t-hitung $=2,909>\mathrm{t}$-tabel $=$ 1,960), dan untuk nilai signifikan $($ Sig $=0,005<0,05)$, maka langkah keputusan dapat dinyatakan $\mathrm{H} 0$ ditolak dan Ha diterima. Dan dapat 
disimpulkan bahwa variabel orientasi pelanggan (X3) berpengaruh signifikan, terhadap kepuasan pelanggan (Y) Olive fried chicken di Jalan Glagahsari Yogyakarta.

d. Pengaruh Komunikasi Terhadap Kepuasan Pelanggan.'

Hasil perhitungan dengan menggunakan program SPSS 16.0 diperoleh nilai t-hitung sebesar 1,453. Tingkat signifikansi $\alpha / 2$ adalah 5\%/2 menjadi $2,5 \%$ atau 0,025. Dan df atau degree of freedom adalah 93 dapat dilihat ditabel bagian baris residual. Sedangkan ttabel adalah 1,960.

Nilai t-hitung lebih besar dari t-tabel (t-hitung $=1,453<\mathrm{t}$-tabel= 1,960), dan untuk nilai signifikan $(\mathrm{Sig}=0,150>0,05)$, maka langkah keputusan dapat dinyatakan $\mathrm{H} 0$ diterima dan Ha ditolak. Dan dapat disimpulkan bahwa variabel komunikasi (X4) tidak berpengaruh signifikan, terhadap kepuasan pelanggan (Y) Olive fried chicken di Jalan Glagahsari Yogyakarta.

Variabel komunikasi tidak signifikan, karena responden penelitian ini adalah orang yang sudah/sedang belanja makan di outlet Olive fried chicken. Maka mereka tidak terpengaruh oleh ada tidaknya iklan atau komunikasi.

e. Pengaruh Manfaat Hubungan Terhadap Kepuasan Pelanggan.

Hasil perhitungan dengan menggunakan program SPSS 16.0 diperoleh nilai t-hitung sebesar 2,052. Tingkat signifikansi $\alpha / 2$ adalah 5\%/2 menjadi $2,5 \%$ atau 0,025. Dan df atau degree of freedom adalah 93 dapat dilihat ditabel bagian baris residual. Sedangkan ttabel adalah 1,960.

Nilai thitunglebih besar dari ttabel (t-hitung $=2,052<\mathrm{t}$-tabel $=$ 1,960), dan untuk nilai signifikan $(\mathrm{Sig}=0,043<0,05)$, maka langkah keputusan dapat dinyatakan $\mathrm{H} 0$ ditolak dan Ha diterima. Dan dapat disimpulkan bahwa variabel manfaat hubungan (X5) berpengaruh signifikan, terhadap kepuasan pelanggan (Y) Olive fried chicken di Jalan Glagahsari Yogyakarta.

f. Pengaruh Harga Terhadap Kepuasan Pelanggan.

Hasil perhitungan dengan menggunakan program SPSS 16.0 diperoleh nilai t-hitung sebesar 3,209. Tingkat signifikansi $\alpha / 2$ adalah 5\%/2 menjadi $2,5 \%$ atau 0,025. Dan df atau degree of freedom adalah 93 dapat dilihat ditabel bagian baris residual. Sedangkan ttabeladalah 1,960.

Nilai t-hitung lebih besar dari t-tabel (t-hitung $=3,209>\mathrm{t}$-tabel $=$ 1,960), dan untuk nilai signifikan $(\operatorname{Sig}=0,002<0,05)$, maka langkah keputusan dapat dinyatakan H0 ditolak dan Ha diterima. Dan dapat disimpulkan bahwa variabel harga (X6) berpengaruh signifikan, terhadap kepuasan pelanggan (Y) Olive fried chicken di Jalan Glagahsari Yogyakarta.

5. Hasil Uji Simultan (Uji F)

Hasil analisis Uji Simultan (Uji F)

\begin{tabular}{|l|r|r|r|r|r|}
\hline \multicolumn{1}{|c|}{ Model } & $\begin{array}{c}\text { Sum of } \\
\text { Squares }\end{array}$ & \multicolumn{1}{c|}{ Df } & $\begin{array}{c}\text { Mean } \\
\text { Square }\end{array}$ & \multicolumn{1}{c|}{ F } & Sig \\
\hline Regression & 65.151 & 6 & 10.858 & 29.833 & $.000^{\mathrm{a}}$ \\
\hline Residual & 33.849 & 93 & .364 & & \\
\hline Total & 99.000 & 99 & & & \\
\hline \multicolumn{7}{c}{ dari olah data F }
\end{tabular}
tabelterdapat dikolom degree of freedom baris regression dengan residual, yaitu 6 untuk regression dan 93 untuk residual. Artinya kolom 6 baris 93, dan didapatkan Ftabel 2,17, untuk nilai $\mathrm{F}$ hitung 29,568 ( $\mathrm{F}$ hitung= $29,833>\mathrm{F}$ tabel $=2,17$ ).

Penelitian dinyatakan $\mathrm{H} 0$ diterima dan $\mathrm{Ha}$ ditolak, apabila probabilitas signifikan $>0,05$. Sedangkan $\mathrm{H} 0$ ditolak dan $\mathrm{Ha}$ diterima, apabila probabilitas signifikan $<0,05$. Nilai signifikansi 0,000 , nilai signifikansi lebih kecil dari pada 0,05 (Sig $=0,000$ 
$<$ 0,05). Maka dapat dijelaskan $\mathrm{H} 0$ ditolak dan Ha diterima, yang berarti variabel lingkungan fisik (X1), variabel kualitas makanan (X2), orientasi pelanggan (X3), komunikasi (X4), manfaat hubungan (X5), dan harga (X6). Dapat disimpulkan secara simultan mempunyai pengaruh yang signifikan terhadap variabel dependen kepuasan pelanggan (Y), dalam mengkonsumsi Olive fried chicken di Jalan Glagahsari Yogyakarta.

\section{Hasil Uji Koefisien Determinasi}

Hasil analisis Uji Koefisien Determinasi $\left(\mathrm{R}^{2}\right)$

\begin{tabular}{|c|c|r|r|c|}
\hline Model & $\mathrm{R}$ & R Square & $\begin{array}{c}\text { Adjusted R } \\
\text { Square }\end{array}$ & $\begin{array}{c}\text { Std. Error of the } \\
\text { Estimate }\end{array}$ \\
\hline $\mathrm{l}$ & $.811^{\mathrm{a}}$ & .658 & .636 & .60330051 \\
\hline
\end{tabular}

Berdasarkan hasil penelitian dan angka tabel di atas diperoleh dengan besarnya koefisien determinasi (R2) adalah 0,658. Artinya, pengaruh semua variabel independen terhadap perubahan nilai variabel dependen adalah $65,8 \%$ dan sisanya sebesar $34,2 \%$ yang dipengaruhi oleh variabel lain yang tidak diteliti. Hal tersebut bisa diartikan bahwa besarnya pengaruh variabel independen variabel lingkungan fisik (X1), variabel kualitas makanan (X2), orientasi pelanggan (X3), komunikasi (X4), manfaat hubungan (X5), dan harga (X6) terhadap kepuasan pelanggan $(\mathrm{Y})$.

\section{KESIMPULAN DAN SARAN}

\section{Kesimpulan}

1. Dari hasil uji parsial (uji t), maka peneliti menarik kesimpulan bahwa untuk masing-masing variabel yaitu variabel kualitas makanan (X2) dan komunikasi (X4) tidak mempengaruhi kepuasan pelanggan (Y). Sedangkan untuk variabel lingkungan fisik (X1), orientasi pelanggan (X3), manfaat hubungan (X5), dan harga (X6) dapat disimpulkan bahwa uji secara parsial (Uji t) berpengaruh signifikan terhadap kepuasan pelanggan (Y) dalam mengkonsumsi Olive fried chicken di Jalan Glagahsari Yogyakarta.

2. Dari hasil perhitungan uji simultan (uji F), didapat Sig $<\alpha=5 \%$ atau $0,000<$ $5 \%$, karena Sig $<\alpha=5 \%$. Maka dapat disimpulkan bahwa variabel lingkungan fisik (X1), kualitas makanan (X2), orientasi pelanggan (X3), komunikasi (X4), manfaat hubungan (X5), dan harga (X6) bahwa secara uji simultan (Uji F) berpengaruh signifikan terhadap kepuasan pelanggan (Y) rumah makan cepat saji Olive fried chicken di Jalan Glagahsari Yogyakarta.

\section{Saran}

Saran yang diberikan kepada perusahaan Olive fried chicken di Jalan Glagahsari Yogyakarta, agar perusahaan dapat lebih memperhatikan dan mempertahankan kualitas layanan yang sudah berjalan. Serta meningkatkan kualitas layanan yang sekiranya belum diperhatikan. Untuk mempertahankan kepuasan pelanggan terhadap layanan yang sudah didapat di Olive fried chicken, dan untuk mempertahankan kebaradaan Olive fried chicken di tengah-tengah persaingan kuliner yang semakin berkembang pesat di Indonesia saat ini terutama tentang kualitas makanan.

Langkah yang bisa dilakukan untuk mempertahankan dan meningkatkan kualitas layanan adalah dengan cara memberikan trainningterhadap karyawan baru untuk memberikan wawasan tentang job descreption yang dilakukan masingmasing karyawan, serta diberi pemahaman tentang melayani konsumen. Untuk lebih efektif lagi bagi karyawan yang mengikuti trainning, agar diberikan pengawasan dan teguran, apabila melakukan kesalahan yang sudah ditetapkan sesuai SOP (standart operating) oleh perusahaan rumah makan cepat saji Olive fried chicken. 


\section{DAFTAR PUSTAKA}

Amanah, Dita. (2010). Pengaruh Harga Dan Kualitas Produk Terhadap Kepuasan Konsumen Pada Majestyk Bakery \& Cake Shop Cabang H.M Yamin Medan. Jurnal Keuangan \& Bisnis. Volume 2. No 1.

Burgo dan Huffner. (2002). Human Communication. London: Sage Publication.

Cooper, D.R., dan Schindler, P.S. (2001). Bussines Research Methods. Boston: Mc Graw Hill Book Co.

Ferdinand. (2006). Structural Equation Modeling dalam Penelitian Manajemen. Semarang: Badan Penerbit Universitas Diponegoro.

Ghozali, Imam. (2005). Aplikasi Analisis Multivariate dengan Program SPSS. Semarang: Badan Penerbit Universitas Diponegoro.

Hair, Joseph F., JR., Rolp E Adreson, Ronald L, Tatham and, Wiliam L Black. (1998). Multivariate Data Analysis. USA: Prentice Hall International, Inc.

Indrianto, Nur dan Supomo Bambang. (2002). Metodelogi Penelitian Bisnis. Yogyakarta: BPFE.

Kotler, Philip. (1997). Manajemen Pemasaran (Analisis, Perencanaan, Implementasi, dan Kontrol). Jakarta: PT. Prenhallindo.

Kotler, Ang, Leong dan Tan. (1999). Manajemen Pemasaran Perspektif Asia. Jilid 1. Yogyakarta: Andi Yogyakarta.

Kotler, Philip. (2005). Manajemen Pemasaran. Jilid Pertama. Jakarta: Erlangga.

Kotler dan Keller. (2009). Manajemen Pemasaran. Edisi Tigabelas. Jilid 1. Jakarta: Erlangga.
Lupiyoadi, Rambat dan A. Hamdani. (2006). Manajemen Pemasaran Jasa. Edisi Kedua. Jakarta: Salemba Empat.

Sihombing, Umberto. (2004). Pengaruh Keterlibatan Dalam Pengambilan Keputusan Penilaian Pada Lingkungan Kerja dan Motivasi Berprestasi Terhadap Kepuasan Kerja Pamong. http://www.dupdiknas.go.id. Diakses 21 Oktober 2014.

Sugiyono. (2004). Metode Penelitian Bisnis. Bandung: CV. Alfabeta.

Swastha, Basu dan Irawan. (1981). AzasAzas Marketing. Edisi Kedua. Yogyakarta: Liberty Offset.

Vanniarajan. (2009). Dineserv: A Tool for Measuring Service Quaity in Restaurants. Jurnal. Vol. 4. Issue 3. 